\title{
Aprendizagem Baseada em Projetos na Informática em Saúde: Desenvolvendo Aplicativos com App Inventor
}

\author{
Lidiany Cerqueira Santos - UFS - lidianycs@ufs.br \\ Danilo Ferreira Neves - PROCC/UFS - danilo.neves@ufs.br \\ Hélio Cardoso de Moura Filho - UFS - helio.cardoso@ ufs.br \\ Fabrício dos Santos Menezes - UFS/USP - fabriciomenezes@msn.com
}

Resumo: A informática se tornou essencial na área da saúde. Políticas de informatização vem sendo implantadas pelo governo brasileiro para capacitar profissionais e acadêmicos, estabelecendo novas relações com a tecnologia e permitindo idealizar novas aplicações de recursos computacionais. O objetivo desse trabalho é relatar e avaliar uma experiência de ensino baseada na Aprendizagem Baseada em Projetos em uma disciplina de Informática Aplicada à Saúde para graduação. $\mathrm{Na}$ disciplina, foi proposto o desenvolvimento de aplicativos móveis para a saúde. A turma contou com a participação de 21 alunos que foram avaliados qualitativamente por dois surveys. Todos os alunos completaram a disciplina e relataram um impacto positivo na sua formação. Cinco aplicativos foram construídos e uma nova percepção de tecnologia foi adquirida, 15 estudantes afirmaram estar motivados para aprender novas tecnologias e 16 se consideraram aptos para desenvolver novos aplicativos.

Palavras-chave: Aprendizagem Baseada em Projetos, Informática em Saúde, Educação.

\section{Project-Based Learning in Health Informatics: Developing Applications with App Inventor}

Abstract: Computing has become essential to the health field. Informatization policies have been implemented by the Brazilian government to train professionals and academics, establishing new relationships with technology and allowing to idealize new applications of computational resources. This work aims to report and evaluate a teaching experience based on Project-Based Learning in an undergraduate subject of Health Informatics. The development of mobile applications for health field has been proposed in the subject. The class had 21 students who were evaluated qualitatively by two surveys. All students completed the course and reported a positive impact of the discipline on their training. Five applications were built and a new perception of technology was achieved, 15 students said to be more motivated to learn new technologies and 16 reported to be able to develop new applications.

Keywords: Project-Based Learning, Health Informatics, Education.

\section{Introdução}

A área da saúde tem se beneficiado pelos avanços nas Tecnologias Digitais da Informação e Comunicação (TDIC). A informática tornou-se essencial para a realização de diversas atividades na área como a prática de vigilância, monitoramento de agravos, indicadores de morbidade e mortalidade, suporte à pesquisa, à gestão e apoio à tomada de decisão (Cardoso et al., 2008; Nichiata et al., 2003). 
O Ministério da Saúde definiu como um de seus objetivos setoriais prioritários, a construção estratégica de uma política de informação e informática em saúde. A Política Nacional de Informação e Informática em Saúde (PNIIS) do Sistema Único de Saúde (SUS) foi criada para atender as demandas de informatização do setor e teve sua última versão publicada em 2016 pelo Ministério da Saúde (BRASIL, 2016). A PNIIS tem por objetivo a informatização dos processos na área da saúde, tanto nos cuidados individuais quanto nas ações de saúde coletiva, aumentando a eficiência e a qualidade dos serviços por meio das TDIC.

Essa política prevê a necessidade de ensino da informática aplicada à saúde nos cursos de graduação e também nos programas de educação permanente, estabelecendo relações entre as TDICs e a práxis profissional da saúde, contribuindo, desta forma, para a melhoria do processo de aprendizagem e permitindo que os estudantes possam idealizar a aplicação das tecnologias na sua realidade profissional (Cardoso et al., 2008).

Contudo, apesar da crescente importância para a área, a oferta da disciplina informática em saúde nos cursos de graduação ainda é escassa, encontrando dificuldades pela falta de profissionais capacitados para o ensino e por uma infraestrutura inadequada (Santos, Guimarães, \& Abe, 2017; Sanches et al., 2011).

Dando continuidade aos estudos realizados por Santos et al (2018), o presente trabalho relata a experiência e as possibilidades da prática docente no ensino de informática em saúde. Utilizando como base de ensino uma abordagem de Aprendizagem Baseada em Projetos (ABP), um modelo que encoraja estudantes a resolverem problemas reais (Marzano, 2007; Bender, 2015), a pesquisa foi motivada pela oportunidade de enriquecimento educacional e profissional dos alunos (Masson et al. 2012; Pereira, et al. 2017; Chiesa et al., 2007) e pela oportunidade de avaliar a adoção da ABP no contexto da informática em saúde.

O estudo foi realizado na disciplina optativa Informática Aplicada à Saúde, ofertada pelo Departamento de Educação em Saúde da Universidade Federal de Sergipe. A disciplina apresenta conceitos introdutórios de programação, desenvolvimento e prototipação sobre a perspectiva da plataforma de criação de aplicativos móveis App Inventor $^{1}$. Os participantes foram estimulados a pensar em projetos reais, identificar oportunidades, pesquisar e projetar aplicações em suas áreas de estudo.

O artigo está organizado da seguinte maneira: a Seção 2 detalha a metodologia utilizada; a Seção 3 apresenta os resultados obtidos; Seção 4 apresenta às ameaças a validade e a Seção 5 traz as conclusões e considerações finais.

\section{Metodologia}

A pesquisa foi desenvolvida sobre uma abordagem qualitativa, aplicando um método de caráter exploratório. O trabalho foi realizado na turma de Informática Aplicada à Saúde, disciplina optativa com carga horária de $60 \mathrm{hrs} \mathrm{destinada} \mathrm{a} \mathrm{alunos} \mathrm{de} \mathrm{graduação.}$ Participaram da turma 21 estudantes dos cursos de Odontologia, Fonoaudiologia e Fisioterapia. A docente que orientou os projetos dos discentes possui Bacharelado em Engenharia de Computação e Mestrado em Ciência da Computação, atuando na área de Engenharia de Software e Informática em Saúde.

A nível exploratório, dois Surveys foram aplicados no decorrer da disciplina. Ambos foram desenvolvidos sobre a escala Likert de 5 pontos com acréscimo de questões 
subjetivas. O Survey pré-teste, primeiro questionário aplicado no início do curso, teve como finalidade conhecer as percepções dos estudantes em relação à área de computação, o relacionamento com o uso de tecnologias, o conhecimento de informática e o interesse em desenvolvimento de softwares. O Survey Pré-Teste pode ser visualizado na Figura 1.

\begin{tabular}{|c|c|c|}
\hline \multicolumn{3}{|c|}{ Questionário Pré-Teste } \\
\hline \multicolumn{3}{|l|}{ 1.Qual a sua idade? } \\
\hline $\begin{array}{l}\text { 2.Quanto tempo você utiliza o } \\
\text { smartphone ao longo do dia? }\end{array}$ & \multicolumn{2}{|c|}{$\begin{array}{c}\text { Menos de } 2 \text { horas } \square \text { Entre } 2 \text { e } 5 \text { horas } \square \text { Entre } 5 \text { e } 10 \text { horas } \square \text { Mais de } 10 \\
\text { horas } \square \text { Não possuo um smartphone } \square\end{array}$} \\
\hline \multicolumn{2}{|c|}{$\begin{array}{l}\text { 3.Você costuma utilizar o smartphone para estudar ou realizar atividades } \\
\text { relacionadas ao seu curso? }\end{array}$} & Nunca $\square \square \square \square \square$ Sempre \\
\hline \multicolumn{2}{|c|}{$\begin{array}{l}\text { 4.Você conhece ou utiliza aplicativos para tablets/smartphones } \\
\text { relacionados ao seu curso/área de estudo? }\end{array}$} & $\operatorname{Sim} \square$ Não $\square$ \\
\hline \multicolumn{3}{|c|}{ 5.Em caso positivo, informe quais aplicativos você conhece ou utiliza. } \\
\hline \multicolumn{2}{|c|}{ 6.Você já pensou em desenvolver um aplicativo para smartphones/tablets? } & $\operatorname{Sim} \square$ Não $\square$ \\
\hline \multicolumn{2}{|c|}{$\begin{array}{l}\text { 7.Em caso positivo, o que the motivou a pensar em desenvolver um } \\
\text { aplicativo? Qual a sua finalidade? }\end{array}$} & \\
\hline \multicolumn{2}{|c|}{ 8.Como você classificaria seus conhecimentos sobre informática? } & Nenhum $\square \square \square \square \square$ Avançado \\
\hline \multicolumn{2}{|c|}{ 9.Como você classificaria seus conhecimentos sobre programação? } & Nenhum $\square \square \square \square \square$ Avançado \\
\hline \multicolumn{2}{|c|}{ 10.Você já se interessou por aprender a programar? } & $\operatorname{Sim} \square$ Não $\square$ \\
\hline \multicolumn{2}{|c|}{11.0 que você espera aprender nesta disciplina? } & \\
\hline
\end{tabular}

Figura 1. Survey aplicado na primeira aula.

O Survey Pós-Teste, questionário final respondido ao término da disciplina, verificou o nível de absorção dos conceitos, as dificuldades encontradas, as mudanças nas percepções em relação a área e a metodologia ABP empregada no ensino. O Survey Pós-Teste é apresentado na Figura 2. Os alunos foram informados previamente da finalidade da pesquisa e de que não seriam identificados ou avaliados por meio dos questionários.

\begin{tabular}{|c|c|c|}
\hline \multicolumn{3}{|c|}{ Questionário Pós-Teste } \\
\hline \multicolumn{2}{|c|}{ 1.Como você classificaria seus conhecimentos sobre informática? } & 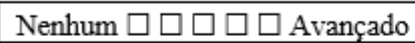 \\
\hline \multicolumn{2}{|c|}{$\begin{array}{l}\text { 2.Como você classificaria seus conhecimentos sobre desenvolvimento de } \\
\text { programas (aplicativos)? }\end{array}$} & Nenhum $\square \square \square \square \square$ Avançado \\
\hline \multicolumn{2}{|c|}{$\begin{array}{l}\text { 3. Quanto ao grau de dificuldade, você considera que a criação de } \\
\text { aplicativos é? }\end{array}$} & Muito dificil $\square \square \square \square \square$ Fácil \\
\hline \multicolumn{2}{|c|}{$\begin{array}{l}\text { 4.Como você avalia a dificuldade para utilizar a ferramenta App Inventor } \\
\text { no desenvolvimento de aplicativos? }\end{array}$} & Muito difícil $\square \square \square \square \square$ Fácil \\
\hline $\begin{array}{l}\text { 5.As habilidades adquiridas ao longo da disciplina } \\
\text { permitem que você desenvolva um aplicativo? }\end{array}$ & \multicolumn{2}{|c|}{ Discordo totalmente $\square \square \square \square \square$ Concordo totalmente } \\
\hline \multicolumn{2}{|l|}{ 6.Você tem interesse em continuar criando aplicativos? } & Sim $\square$ Não $\square$ \\
\hline \multicolumn{2}{|c|}{$\begin{array}{l}\text { 7.Você teve dificuldades na criação de aplicativos? Em caso positivo, } \\
\text { quais? }\end{array}$} & \\
\hline \multicolumn{3}{|c|}{\begin{tabular}{l|l} 
8.Quais conceitos foram aprendidos na disciplina especificamente? & \\
\end{tabular}} \\
\hline 9.Você se sentiu motivado(a) durante a disciplina? & \multicolumn{2}{|c|}{ Discordo totalmente $\square \square \square \square \square$ Concordo totalmente } \\
\hline $\begin{array}{l}\text { 10.A disciplina contribuiu positivamente, } \\
\text { agregando valor para a sua formação? }\end{array}$ & \multicolumn{2}{|c|}{ Discordo totalmente $\square \square \square \square \square$ Concordo totalmente } \\
\hline $\begin{array}{l}\text { 11. A metodologia empregada na disciplina foi } \\
\text { adequada? }\end{array}$ & \multicolumn{2}{|c|}{ Discordo totalmente $\square \square \square \square \square$ Concordo totalmente } \\
\hline $\begin{array}{l}\text { 12.A disciplina contribuiu para a sua formação } \\
\text { acadêmica e profissional? }\end{array}$ & \multicolumn{2}{|c|}{ Discordo totalmente $\square \square \square \square \square$ Concordo totalmente } \\
\hline \multicolumn{3}{|c|}{$\begin{array}{l}\text { 13.Os conceitos aprendidos ao longo da disciplina são de grande } \\
\text { importância para o mercado de trabalho? }\end{array}$} \\
\hline \multicolumn{3}{|c|}{ 14.Você recomendaria a disciplina para outros colegas? } \\
\hline \multicolumn{2}{|c|}{$\begin{array}{l}\text { 15.Apresente a sua opinião sobre a disciplina e a metodologia empregada } \\
\text { (sugestões de melhoria, percepção pessoal, ambiente, contribuições, } \\
\text { pontos positivos e negativos). }\end{array}$} & \\
\hline
\end{tabular}

Figura 2. Survey aplicado ao final da disciplina.

Alinhado à $\mathrm{ABP}$, todo plano de ensino foi montado priorizando a criatividade dos alunos e os desafiando a realizar os projetos de forma autônoma, pela pesquisa e aplicação 
do seu conhecimento (Markham, 2008; Marzano, 2007). Nesse contexto, a docente exercia a motivação e organização, apresentando um planejamento rigoroso, incluindo cronogramas e estratégias de gerenciamento, além da própria avaliação dos resultados que exigiam conhecimentos sólidos sobre as técnicas necessárias para construção dos projetos (Masson et al., 2012).

Foi estabelecido como plano de ensino, o desenvolvimento e entrega de um aplicativo móvel. Como se tratavam de alunos com pouco conhecimento de programação, o projeto foi elaborado na plataforma App Inventor que possibilita a prática de programação gráfica baseada em blocos lógicos (Wolber, 2011). Sem uma linguagem de programação específica, a ferramenta facilita o desenvolvimento de aplicativos funcionais para programadores iniciantes. Para construção do projeto e alinhamento à $\mathrm{ABP}$, as aulas seguiram uma divisão baseada em 3 fases: Planejamento, Desenvolvimento e Avaliação. O fluxograma baseado no plano pedagógico da disciplina é apresentado a seguir na Figura 3.

- $\quad$ Planejamento: nessa fase os discentes foram instruídos a realizar uma busca por aplicativos na área da saúde e avaliar uma lista de aplicativos sugeridos pela docente. É necessário despertar o interesse sobre o conteúdo e, sobretudo, apresentar as possibilidades de desenvolvimento (Martins, 2001).

Logo depois, os alunos foram separados em grupos de no máximo 5 integrantes e iniciado um processo de Brainstorming para definição do projeto a ser desenvolvido. A discussão de ideias seguiu de forma autônoma pelos discentes, exercitando a comunicação em grupo e a capacidade de criação (Baron et al., 1998; Pereira et al.; 2017).

Com as propostas definidas, foi avaliada a viabilidade e os recursos necessários para o desenvolvimento. Caso o projeto não fosse viável, os alunos realizavam um novo Brainstorming. O ciclo ocorreu até que um projeto compatível com a realidade de conhecimento e instrumentação dos alunos fosse proposto.

Os projetos definidos foram apresentados para a turma com auxílio do Project Model Canvas (Campos, 2016), especificando o público alvo, objetivos e benefícios.

- Desenvolvimento: é dado início a construção do aplicativo em si. Alternando entre prática e teoria, foram ministradas aulas de programação contextualizadas na plataforma App Inventor, com lições de algoritmos e prototipação ao mesmo tempo que era desenvolvido o projeto do aplicativo.

Ao fim das aulas conceituais uma apresentação parcial do aplicativo foi realizada. Em cada apresentação, os demais grupos foram encorajados a opinar com sugestões e críticas. Após os seminários, sob orientação docente, os alunos iniciaram um ciclo de manutenção e aperfeiçoamento da aplicação até o prazo final de entrega dos projetos.

- Avaliação: na apresentação final, realizada no último encontro, as equipes entregaram o aplicativo desenvolvido. Os discentes demonstraram o aplicativo em execução, discutiram o planejamento inicial e as mudanças necessárias para entrega do produto final. Por fim, foi realizada uma votação e as equipes escolheram o melhor projeto. 


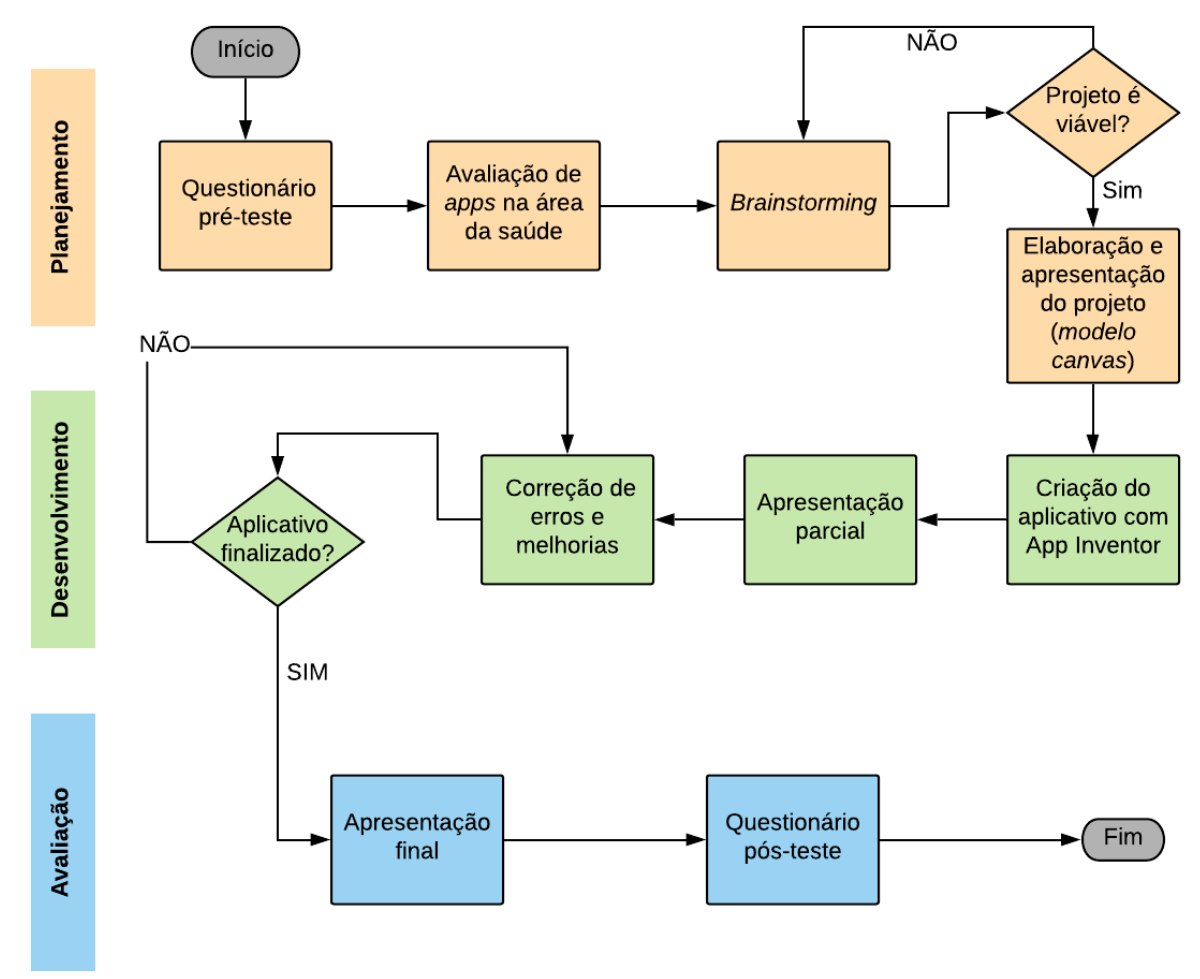

Figura 3. Fluxograma de atividades realizada na disciplina.

\section{Resultados}

Os dados apresentados nesta seção foram obtidos a partir da avaliação dos surveys e dos projetos desenvolvidos em aula. A análise dos dados permitiu traçar um perfil dos discentes, a mudança de percepção em relação a tecnologia e da eficiência da metodologia $\mathrm{ABP}$.

A turma foi composta por 21 discentes, com grande maioria feminina (16 alunas), idade entre 18 e 23 anos, dos cursos de Odontologia (13 discentes), Fisioterapia (5 discentes) e Fonoaudiologia (3 discentes). Mais da metade desses alunos são consumidores assíduos de tecnologia móvel, 60\% afirmaram utilizar o aparelho por 10 horas ou mais ao dia e $55 \%$ relataram que também usam o aparelho para fins acadêmicos, citando como exemplo os aplicativos Anatomy Learning e 3Dcel.

Ainda em relação ao perfil, os alunos alegaram possuir baixo conhecimento técnico em informática, dentre o total de participantes $45 \%$ afirmam possuir um conhecimento médio e $40 \%$ consideram seu conhecimento básico. A pouca experiência é ainda maior em relação a programação, onde $65 \%$ da turma afirma não ter nenhum conhecimento. Os dados completos estão disponíveis na Figura 4.

Um reflexo da inexperiência em informática e programação é revelado pelas respostas referentes ao desejo de criar aplicativos, $75 \%$ da turma afirmaram que não tinham interesse prévio em desenvolver apps. Entretanto, a maioria dos alunos manifestou o interesse em aprender a programar (80\%), indicando um possível engajamento da turma com relação ao conteúdo programático. 
Conhecimento em Informática

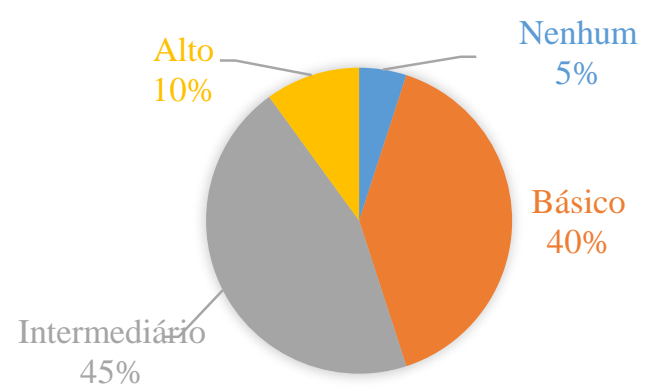

Conhecimento em Programação

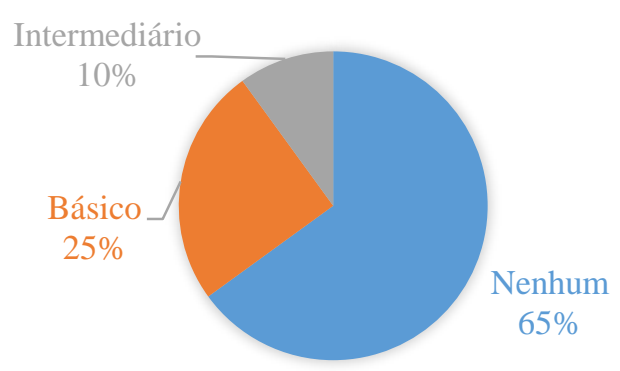

Figura 4. Percepção de conhecimento dos alunos acerca de informática e programação

No decorrer da disciplina, os alunos demonstraram empenho no desenvolvimento das ferramentas, realizando pesquisas bibliográficas para fundamentação teórica, pesquisas de campo, fotografias autorais e ilustrações. Como resultado foram desenvolvidos 5 aplicativos. Como o objetivo da disciplina era primariamente o ensino e a descoberta da tecnologia os aplicativos desenvolvidos não foram publicados.

Na Figura 5, são apresentados 4 dos 5 aplicativos desenvolvidos. Da esquerda para direita: Citologia Básica é um aplicativo didático para o estudo das células; ErgoTAG tem como objetivo orientar sobre a importância de uma postura correta; OdontoKids é destinado à orientar pais e crianças sobre as práticas de uma higiene bucal saudável; e por último, Inervação Didática tem como proposta auxiliar estudantes com conteúdo teórico sobre inervação.
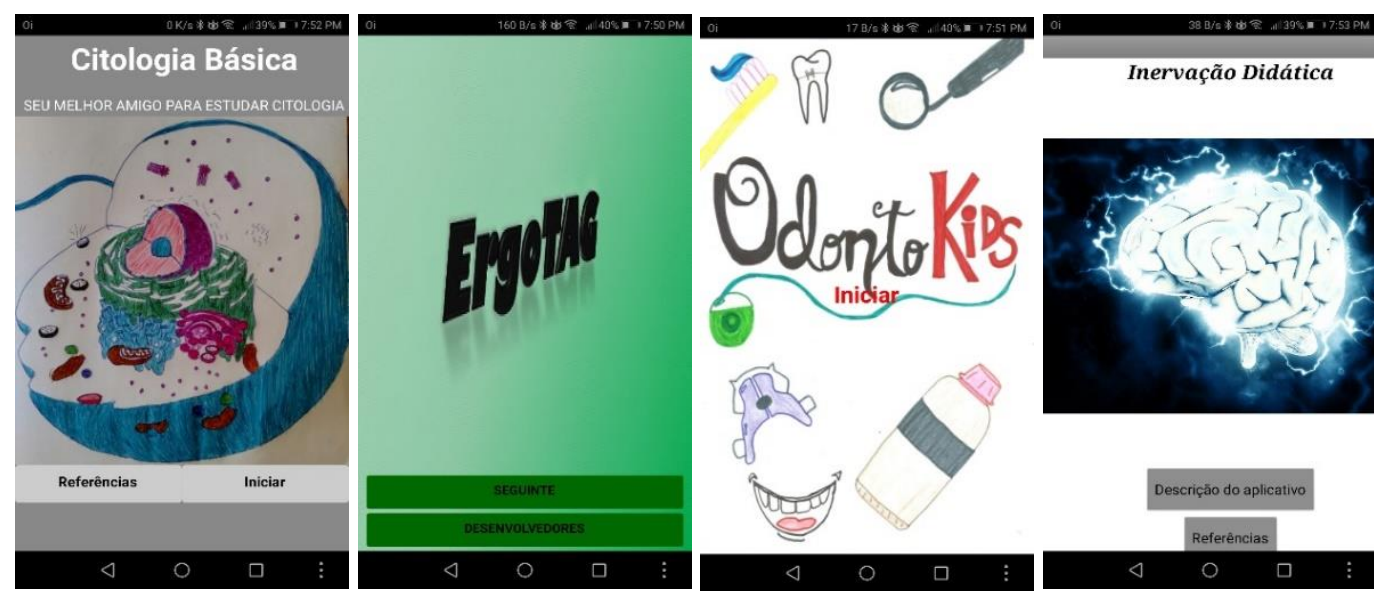

Figura 5. Aplicativos construídos pela turma.

O quinto aplicativo, LabMorfoQuiz (vide Figura 6), teve destaque nas apresentações e foi avaliado como melhor projeto pela turma e pela docente. O grupo desenvolvedor da aplicação, composto por alunos de Odontologia, se preocupou em facilitar o acesso ao conteúdo das disciplinas iniciais para os estudantes calouros da Universidade. Para desenvolver o aplicativo, os discentes fotografaram modelos anatômicos com estruturas internas e externas do corpo humano. Também foram capturadas imagens de lâminas de microscópio e realizado um levantamento bibliográfico para compor a fundamentação teórica do aplicativo. Deste modo, a utilização do app permitiria aos discentes ter acesso ao conteúdo disponível nos laboratórios da Universidade também no seu próprio celular. 


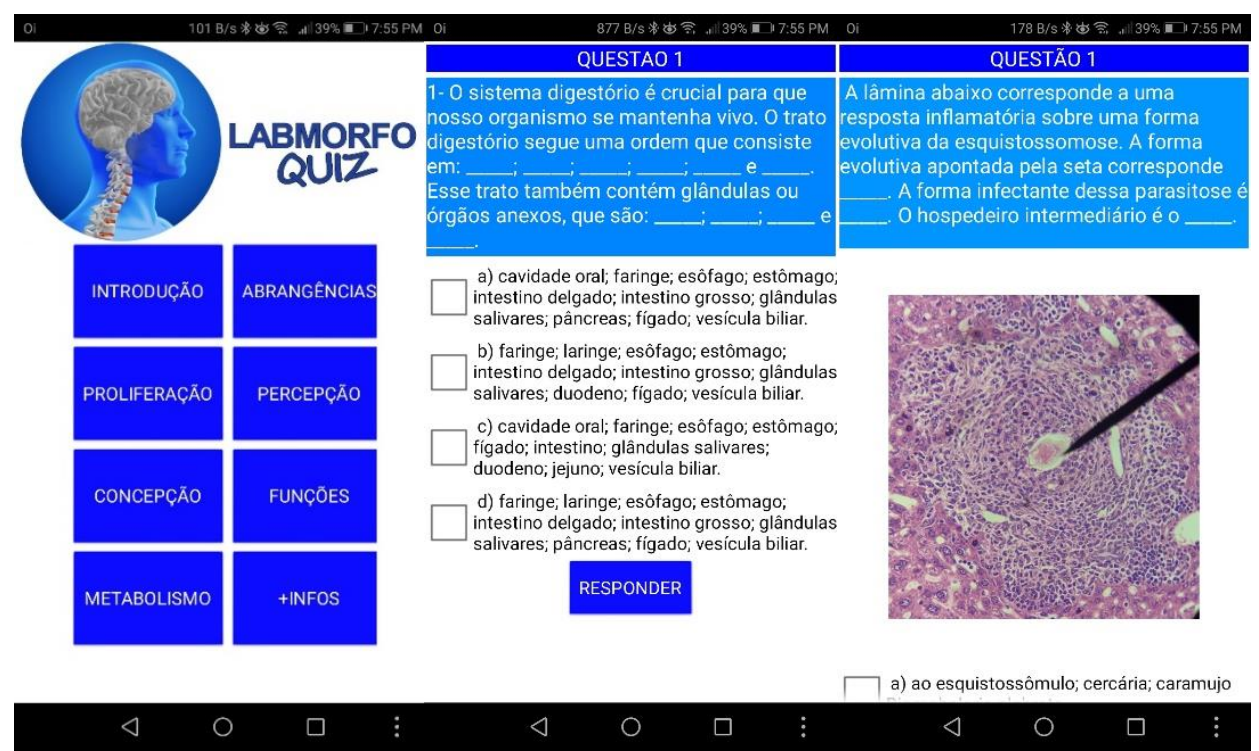

Figura 6. LabMorfo Quiz: eleito o melhor aplicativo pelos próprios alunos.

Todos os aplicativos foram desenvolvidos na plataforma App Inventor, considerada de baixa complexidade por pelo menos 12 estudantes, que facilitou o desenvolvimento dos aplicativos (vide Figura 7). Entretanto, alguns grupos tiveram dificuldades em alguns conceitos mais avançados de programação. Nenhuma das equipes utilizou um banco de dados por exemplo, com isso tiveram que criar muitas telas e inserir demasiada quantidade de informações estáticas, excedendo o limite máximo de telas e tamanho recomendados pela plataforma. Contudo, pelo escopo da disciplina e pela carga horária disponível optou-se por não avançar nos conceitos de banco de dados.

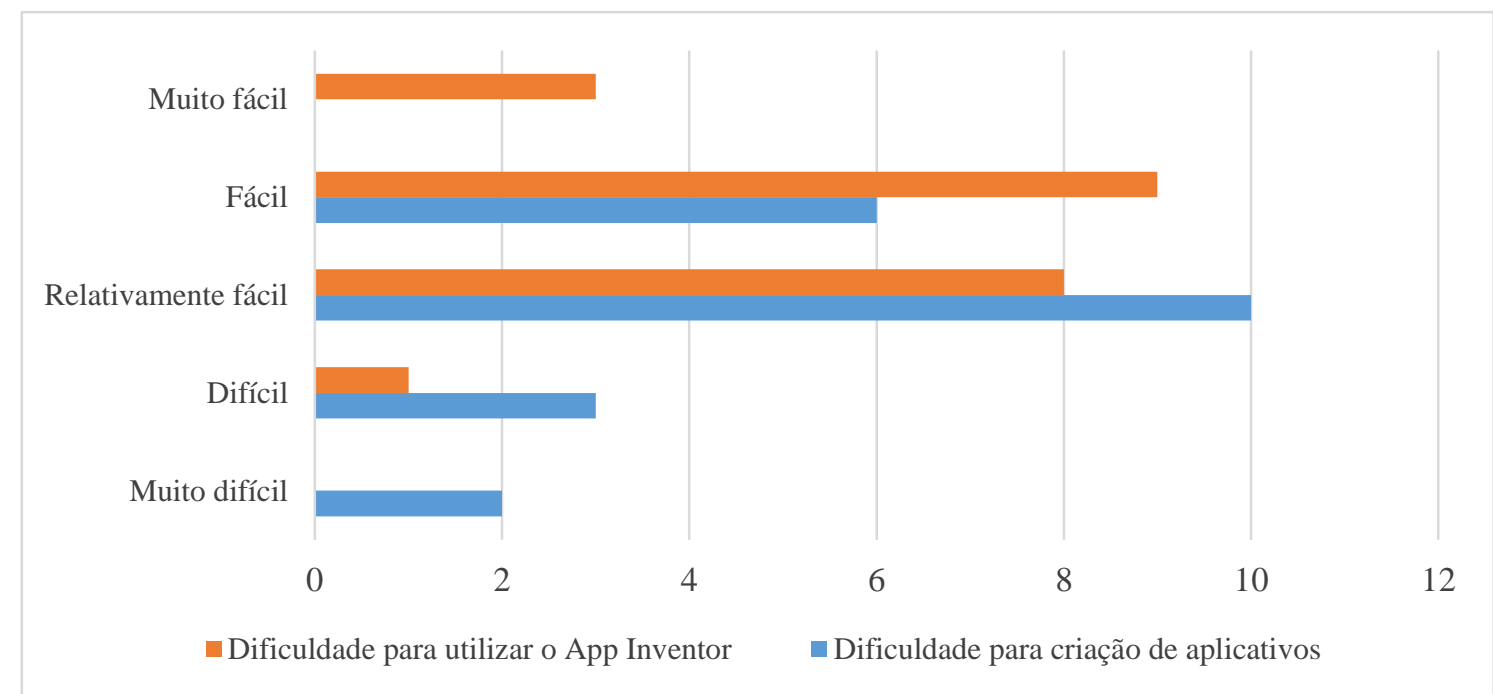

Figura 7. Percepção da dificuldade no uso do App Inventor e criação de aplicações.

Apesar das dificuldades em relação ao conteúdo avançado, 15 dos 21 discentes se mostraram interessados em aprender novas tecnologias e motivados pela proposta de desenvolver e apresentar um aplicativo (vide Figura 8). Ao se auto avaliarem 16 desses alunos se consideraram aptos a criar novas aplicações e tantos outros $(61,9 \%)$ confirmaram interesse em continuar desenvolvendo. 


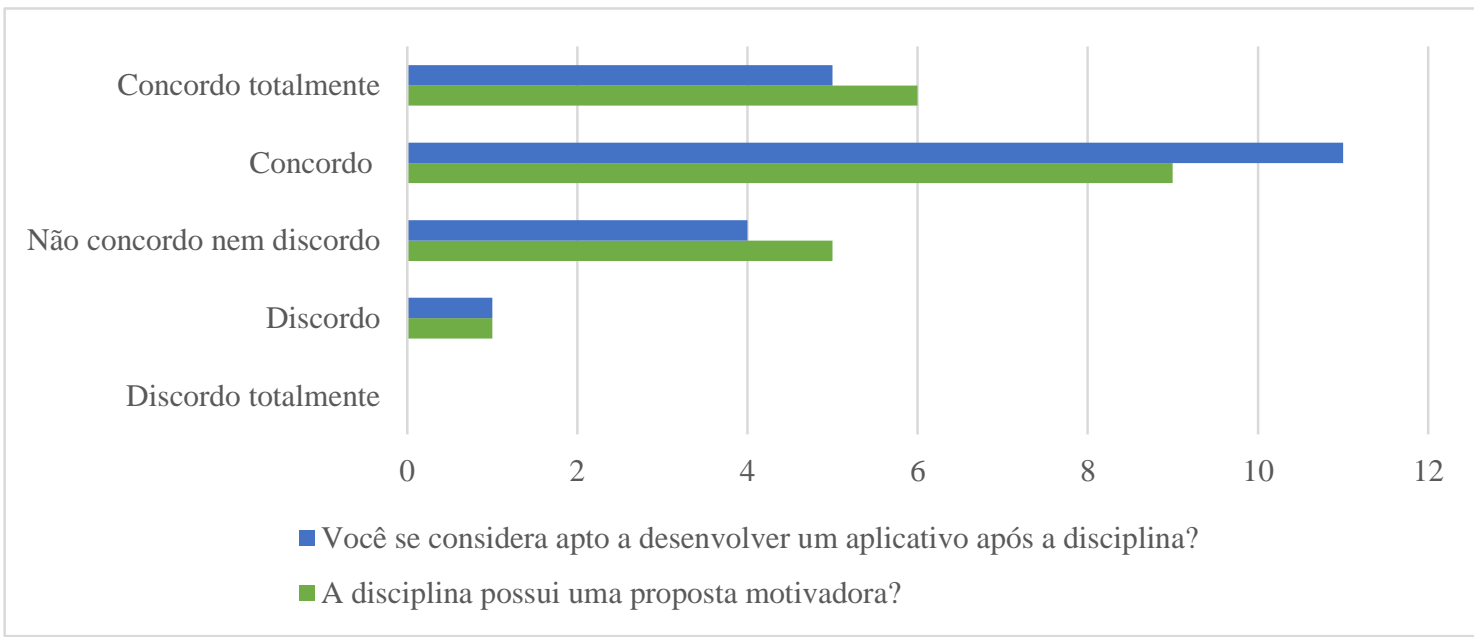

Figura 8. Avaliação sobre motivação e interesse em desenvolver novos aplicativos

$\mathrm{Na}$ última aula, os discentes se mostraram entusiasmados para apresentar os projetos e mostrar o resultado final dos trabalhos. Questionados se a metodologia havia sido adequada, $81 \%$ dos estudantes concordaram, $19 \%$ ficaram neutros e nenhum discordou (vide Figura 9). A maioria dos discentes acredita na contribuição da disciplina para sua formação acadêmica (91,5\%), sendo que alguns expressaram o interesse de apresentar os projetos à comunidade acadêmica em seminários e eventos científicos.

A metodologia $\mathrm{ABP}$ foi adequada?

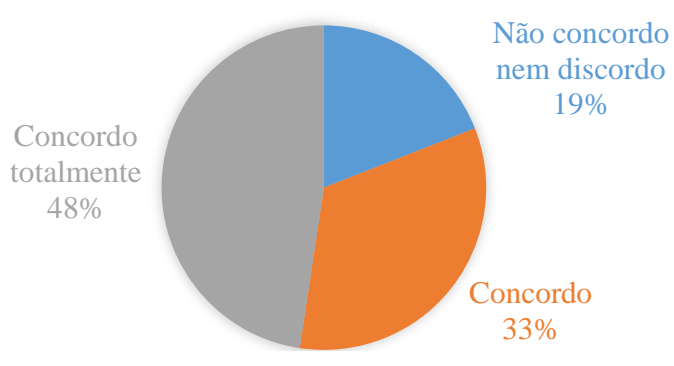

A disciplina contribuiu para a sua formação acadêmica e profissional?

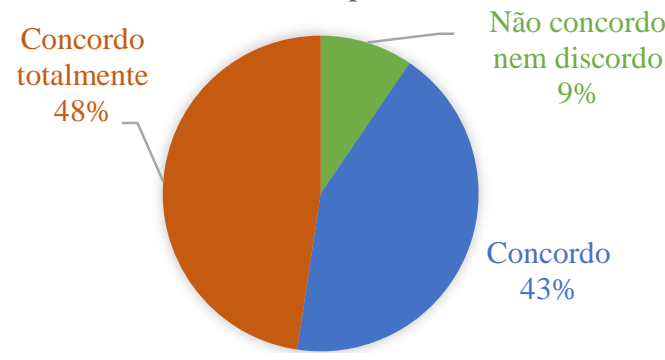

Figura 9. Avaliação da metodologia e das contribuições da disciplina.

\section{Ameaças à Validade}

É possível que problemas possam ter ocorrido durante a coleta e análise dos dados:

- $\quad$ Ameaça Interna: os dados coletados pelo survey podem não refletir o real perfil dos participantes por conter questões que não foram entendidas corretamente. Para mitigar esse problema os questionários foram elaborados e revisados coletivamente, com um pequeno número de questões e uma linguagem simples. Além disso, a aplicação do questionário foi monitorada permitindo que os participantes tirassem dúvidas eventuais.

- Ameaça Externa: a relação interpessoal entre docente e alunos podem levar a respostas com viés emotivo. Contudo, foi explicado de antemão que os questionários não seriam utilizados na avaliação e que os dados seriam coletados de forma anônima. Apesar da tendência dos entrevistados em evitar as opções extremas, foi possível observar que as respostas não apresentaram uma tendência de viés central. 
- $\quad$ Ameaça de Conclusão: a amostra obtida para avaliação da metodologia pode ser considerada pequena por conter apenas 21 registros. Entende-se também que os resultados obtidos neste estudo não podem ser generalizados, uma vez que representam as percepções e experiência dos participantes envolvidos no contexto analisado. Contudo, para avaliar melhor o resultado pretende-se repetir o estudo em outras turmas.

\section{Conclusão}

Esse estudo teve como objetivo a investigação e avaliação qualitativa das contribuições e impactos da ABP na prática do ensino da informática em saúde. A pesquisa foi conduzida em uma turma de 21 alunos da disciplina Informática Aplicada à Saúde e teve como proposta o desenvolvimento de aplicações móveis para a área da saúde. Sobre um método exploratório, a pesquisa foi instrumentada pela aplicação de dois surveys e pela análise qualitativa dos projetos desenvolvidos em sala.

A turma era composta por alunos de Odontologia, Fisioterapia e Fonoaudiologia que até então não tinham nenhum $(65 \%)$ ou limitado $(25 \%)$ conhecimento em programação. Ao mesmo tempo que não expressavam interesse em desenvolver aplicativos móveis (75\%), foi manifestado o desejo de conhecer mais sobre Tecnologia e Programação (80\%).

Utilizando a ABP como método de ensino, os alunos foram direcionados para um caminho no qual precisavam demonstrar iniciativa e proatividade na busca por conteúdo para construção dos aplicativos. O modelo colocou os alunos em um papel diferente do que estão acostumados, saindo do papel de apenas consumidores para o de projetistas. A ABP foi considerada uma metodologia adequada $(81 \%)$ e motivadora $(71,4 \%)$ pelos estudantes.

Ao final do curso, 5 ferramentas foram construídas e uma nova percepção sobre a tecnologia foi estabelecida na turma. Dentre os 21 alunos, 16 se autoavaliaram como aptos para o desenvolvimento de aplicativos e $61,9 \%$ do total manifestaram interesse em continuar desenvolvendo. Em comparação aos resultados apresentados pela turma anterior (SANTOS et al, 2018), na qual não foi utilizado o App Inventor, foi possível observar que os discentes ficaram mais motivados ao conseguir executar e testar os aplicativos desenvolvidos, em lugar dos protótipos de baixa fidelidade apresentados pela turma anterior.

Como consequência do empenho investido, o aplicativo LabMorfoQuiz foi aprovado em um programa de promoção ao ensino que tem como diretrizes alavancar a qualidade e o desempenho acadêmico da instituição. Desse modo, a aplicação está sendo aprimorada para integrar o plano pedagógico de uma das disciplinas obrigatórias do campus, servindo como mais uma opção de estudo aos alunos.

\section{Referências}

BARRON, B.J.S.; et al. Doing with understanding: Lessons from research on problemand project-based learning. Journal of the Learning Sciences, v. 7, n. 3-4, p. 271-311, 1998.

BENDER, W. N. Aprendizagem baseada em projetos: educação diferenciada para o século XXI. [s.1.]: Penso Editora, 2015. 
BRASIL. Política Nacional de Informação e Informática em Saúde. 2016. Disponível em: <http://bvsms.saude.gov.br/bvs/publicacoes/politica_nacional_infor_informatica_saude _2016.pdf>. Acesso em: 10 nov. 2018.

CAMPOS, A. de; et al. Aprendizagem Baseada em Projetos: uma experiência em sala de aula para compartilhamento e criação do conhecimento no processo de desenvolvimento de projetos de software. Revista Competência, v. 9, n. 2, p. 17-35, 2016.

CARDOSO, J. P.; ROSA, V. A.; LOPES, C. R. S; et al. Construção de uma práxis educativa em informática na saúde para ensino de graduação. Ciência \& Saúde Coletiva, v. 13, p. 283-288, 2008.

CHIESA, A. M.; et al. A formação de profissionais da saúde: aprendizagem significativa à luz da promoção da saúde. Cogitare enfermagem, v. 12, n. 2, 2007.

MARKHAM, J. A, T., L., J., R.. Aprendizagem baseada em projetos: guia para professores de ensino fundamental e médio. [s.1.]: Artmed, 2008.

MARTINS, J. S.. O trabalho com projetos de pesquisa do Ensino Fundamental ao Ensino Médio. [s.1.]: Papirus Editora, 2001.

MARZANO, R. J. The art and science of teaching: A comprehensive framework for effective instruction. [s.1.]: Ascd, 2007.

MASSON, T. J.; et al. Metodologia de ensino: aprendizagem baseada em projetos (pbl). In: Anais do XL Congresso Brasileiro de Educação em Engenharia (COBENGE), Belém, PA, Brasil. [s.1.]: sn, 2012.

NICHIATA, L. Y. I.; et al. Relato de uma experiência de ensino de enfermagem em saúde coletiva: a informática no ensino de vigilância epidemiológica. Revista da Escola de Enfermagem da USP, v. 37, n. 3, p. 36-43, 2003.

PEREIRA, S.; et al. A experiência do uso da Aprendizagem Baseada em Projetos como metodologia ativa no Programa de Educação pelo Trabalho para a Saúde na aprendizagem da prática profissional. DEMETRA: Alimentação, Nutrição \& Saúde, v. 12, n. 4, p. 881-898, 2017.

SANCHES, L.M.P.; JENSEN, R.; MONTEIRO, M.I.; et al. Ensino da informática na graduação em Enfermagem de instituições públicas Brasileiras. Revista LatinoAmericana de Enfermagem, v. 19, n. 6, p. 1385-1390, 2011.

SANTOS, M.A.; GUIMARÃES, M.P.; A.B.E., K.C.; O Ensino da Disciplina de Informática em Saúde nos Cursos de Graduação em Enfermagem. Em Rede-Revista de Educação a Distância, v. 4, n. 1, p. 166-173, 2017.

SANTOS, L. C. et al. Prototipação de Aplicativos como Método de Aprendizagem na Informática em Saúde: Um Relato de Experiência. In: Anais do Workshop de Informática na Escola. 2018. p. 90.

WOLBER, D.. App Inventor and Real-world Motivation. In: Proceedings of the 42Nd ACM Technical Symposium on Computer Science Education. New York, NY, USA: ACM, 2011, p. 601-606. (SIGCSE'11). 